\title{
OBITUARIO
}

\section{PROFESOR DR. PEDRO A. TESONE (1934-2018)}

\author{
PROFESSOR DR. PEDRO A. TESONE (1934-2018)
}

Falleció el 18 de enero luego de padecer durante cuatro años diversos problemas de salud que lo deterioraron físicamente.

Siempre lo recordaremos con afecto por su personalidad, afabilidad, sencillez, bondad, honradez y agradable trato. Buen maestro, ejerció su docencia con los integrantes de su Servicio y aquellos que efectuaron pasantías por el mismo, nacionales y extranjeros.

La vida no le fue fácil pero supo con su entereza superar con creces los inconvenientes que se le plantearon. El Dr. Tesone nació con una dificultad visual que recién pudo superar en las postrimerías de su carrera como alumno de Medicina. Para ello contó con la ayuda de uno de esos seres excepcionales que llegaremos a conocer durante nuestra existencia, en su caso el Dr. Martín Roubicek, quien estudió con él los últimos años de su carrera; fue su compañero y el lector de las Materias de Medicina cuando estaba próxima la solución de su padecimiento visual mediante una cirugía que fue exitosa.

Sus padres decidieron que no concurriera a la escuela primaria por temor que un accidente agravara su afección; se presentó como alumno libre y cursó sus estudios secundarios que completó a los 16 años y a los 20 se recibió de Médico. Posteriormente presentó su tesis y se Doctoró. Poseedor de una amplia cultura general y una memoria excepcional, se destacó también en el aspecto musical; como buen pianista junto con un grupo de músicos formó un conjunto de Música de Cámara. Dominaba su lengua natal y los idiomas inglés, francés, alemán, portugués, italiano y parcialmente el ruso. Trabajó hasta consolidarse en su profesión como traductor en Congresos Médicos con traducciones que eran excelentes pues adicionaba a la del idioma sus conocimientos de Medicina. Siempre le agradaron los temas de Historia de la Medicina y esa afinidad lo llevó a realizar publicaciones en las Sociedades en las que se desempeñó durante su carrera. Así surgieron estudios sobre el desarrollo de la nutrición en nuestro país, la historia de la diabetes y del descu- brimiento de la insulina y su logro como medicamento que salvó tantas vidas.

Iniciada su actividad profesional fue médico concurrente en el antiguo Hospital de Clínicas en la $1^{\circ}$ Cátedra de Clínica Médica a cargo del Dr. Egidio Mazzei. Se recibió de Médico Dietólogo en el Instituto Nacional de Nutrición fundado por el Dr. Pedro Escudero siendo sus profesores la primera camada de especialistas discípulos del Maestro.

A fin de mejorar sus conocimientos de la especialidad Nutrición fue concurrente en los Hospitales Rawson (Servicio de Nutrición y Gastronterología, pabellón Olivera) a cargo del Dr. Pedro Landabure; de allí pasó al Servicio de Nutrición del Hospital Ramos Mejía, luego al Hospital Durand en el Servicio de Nutrición y desde éste volvió al Ramos Mejía ya con el nombramiento de Jefe de la Unidad obtenida por concurso, cargo que desempeñó desde 1980 hasta 1993; en ese año pasó a ser Jefe del Departamento de Medicina del mismo Hospital. Colaboró en la Secretaría de Salud del Gobierno de la Ciudad como asesor en Nutrición, coordinó los Programas de Diabetes y la Comisión de Expertos al crear la Red de Diabetes del Programa de año 2000 a 2006. Fue Director de la Carrera de Médico Especialista Universitario en Nutrición del Hospital Ramos Mejía desde 1998 a 2005. Presidió Congresos de la especialidad, trabajó en investigación clínica y se jubiló de la actividad hospitalaria en 2006.

Se desempeñó como Presidente de la Sociedad Argentina de Nutrición en el período 1991- 1992 y de la Sociedad Argentina de Diabetes en 1993-1994. En su actividad docente fue Profesor Regular Adjunto en Nutrición en la UBA y fundó en la Universidad Católica Argentina la Cátedra de Nutrición y fue Director en la Carrera de Especialistas en Nutrición. Quienes lo conocimos recordaremos su paso por nuestras vidas con afecto. Estimado Pedro Tesone, descanse en paz.

Dr. Héctor Valli Dra. Zulema Stolarza 